\title{
Bioética: um encontro com a Fonoaudiologia
}

\section{Bioethics: an encounter with speech, language and hearing sciences}

\author{
Ana Amélia Condúru Vieira \\ Universidade do Amazonas, Belém, Pará, Brasil \\ anameliacvieira@hotmail.com
}

\section{Marcelia Sousa de Sousa}

Universidade do Amazonas, Belém, Pará, Brasil

marceliasousa1986@yahoo.com.br

\author{
Neyla Arroyo Lara Mourão \\ Universidade do Amazonas, Belém, Pará, Brasil \\ n_lara4@yahoo.com.br
}

Resumo: Objetivou-se nesta pesquisa estudar a aplicação da bioética à fonoaudiologia. A metodologia consistiu na aplicação de um questionário a 41 fonoaudiólogos de Belém, visando investigar as questões éticas que envolvem sua rotina, seus conhecimentos sobre bioética e a sua influência em seu exercício profissional. Os resultados mostram que $75 \%$ dos entrevistados já realizaram e/ou esclareceram um diagnóstico difícil; 52\% já realizaram tratamento de pacientes em estado crítico ou com péssimo prognóstico; $80 \%$ já se depararam com um procedimento inadequado de um colega ou de outro profissional da saúde; $71 \%$ já tiveram um paciente que se aborreceu e/ou não colaborou durante um atendimento; 36\% tiveram pacientes que pediram alteração no resultado de um procedimento; $48 \%$ referiram que passaram por problemas de relacionamento profissional; $29 \%$ tiveram impasse na realização de pesquisa; os entrevistados demonstraram que acreditam no auxilio que a bioética representa no trato das questões abordadas neste estudo. Conclui-se que várias questões éticas envolvem a rotina dos fonoaudiólogos, que estes profissionais possuem conhecimentos sobre a bioética e reconhecem o auxílio que esta ciência pode significar em seu desempenho. Por isso, muitas pesquisas precisam ser feitas para detalhar a aplicação da bioética à atuação específica do fonoaudiólogo.

Palavras-chave: Ética. Bioética. Fonoaudiologia. Conduta profissional. 
Abstract: The objective of this investigation was to study the application of bioethics to speech, language and hearing sciences. The methodology consisted of applying a questionnaire to 41 speech, language and hearing therapists in Belém, with the aim of ascertaining the ethical issues involved in their routine, their knowledge of bioethics and its influence on their professional practice. The results showed that $75 \%$ of the interviewees had already made and/or clarified a difficult diagnosis; 52\% had already carried out treatment on patients in a critical state or with a poor prognosis; $80 \%$ had already been presented with an inappropriate procedure performed by a colleague or another healthcare professional; $71 \%$ had already had a patient who was tiresome and/or uncooperative during the attendance; $36 \%$ had had patients who asked for the result from a procedure to be changed; $48 \%$ said that they had gone through professional relationship problems; and $29 \%$ had reached an impasse in conducting investigations. The interviewees showed that they believed in the aid that bioethics would represent in dealing with the issues raised in this study. It was concluded that several ethical issues are involved in speech, language and hearing therapists' routine, and that these professionals had knowledge about bioethics and recognized the aid that this science might signify in their practice. For this reason, many further studies need to be conducted in order to detail the application of bioethics to the specific activities of speech, language and hearing therapists.

Keywords: Ethics. Bioethics. Speech therapy. Professional conduct.

Todos, no exercício de sua profissão, estão sujeitos a adotar condutas inadequadas e, portanto, a cometer erros. Isso induz ao questionamento e às discussões a respeito de falhas cometidas pelos profissionais da área de saúde.

Segundo Ferraz (1), antigamente a população em geral não questionava a conduta do profissional de saúde. Se houvesse falhas, estas eram vistas como fatalidades advindas do tratamento e não se procurava contestar o ato realizado pelo profissional, cujo respeito e confiança eram manifestados por um temor reverencial, fato que já não ocorre nos dias atuais.

Pessini e Barchifontaine (2) referem que a bioética é considerada uma área de conhecimento interdisciplinar recente e que surgiu em função da necessidade de se discutir os efeitos resultantes do avanço tecnológico das ciências da área da saúde, bem como aspectos tradicionais das diversas relações que envolvem os profissionais desta área.

Neste quadro, encontra-se a fonoaudiologia, com seus profissionais dedicados 
ao diagnóstico e tratamento de problemas auditivos, de motricidade orofacial, de linguagem, de voz e de saúde pública.

Pode-se constatar no Código de Ética da Fonoaudiologia (3) que o fonoaudiólogo deve utilizar os conhecimentos e recursos necessários em favor do ser humano e da comunidade, assumir responsabilidades pelos atos praticados, respeitar o paciente e não permitir que este seja desrespeitado. Constata-se, também, que ele deve atuar nos limites de sua competência, nos seguintes procedimentos: avaliação, solicitação, elaboração e realização de exame, diagnóstico, tratamento e pesquisa, emissão de parecer, laudo, docência, responsabilidade técnica, assessoramento, consultoria, coordenação, administração, orientação, realização de perícia e outros que possibilitem atuação profissional plena.

Jardilino e Herrero (4) afirmam que a competência profissional do Fonoaudiólogo não se restringe à capacitação técnico-científica, mas engloba as reflexões sobre sua conduta, para que, consciente de suas responsabilidades sociais, não seja um repetidor de técnicas e tenha atitudes transformadoras da realidade. Goldin (5) ratifica essa ideia, defendendo a necessidade de desenvolver e ampliar os espaços de reflexão sobre os aspectos morais envolvidos na prática profissional dos Fonoaudiólogos.

A fonoaudiologia, como uma profissão da área da saúde, provavelmente, tem muitos interesses na bioética. No entanto, a literatura específica é extremamente escassa, sendo preciso, na maioria das vezes, recorrer a outras áreas, principalmente, à Medicina, para obter dados. Devido à interdisciplinaridade que é característica da bioética, algumas respostas têm sido possíveis de serem obtidas com base no estudo de questões similares das outras áreas da saúde, porém, é questionável se não seria mais efetivo se esse estudo fosse direcionado às questões inerentes à fonoaudiologia.

Diante dos fatos acima citados, tornou-se relevante propor um estudo sobre a aplicação específica da bioética à fonoaudiologia.

\section{Desenho da pesquisa: objetivos e metodologia}

O objetivo geral do estudo foi avaliar a aplicação específica da bioética à fonoaudiologia. Sendo que os objetivos específicos eleitos foram: identificar as questões éticas que envolvem a rotina dos fonoaudiólogos; verificar se os fonoaudiólogos possuem conhecimento sobre bioética e; identificar a influência da bioética no exercício profissional da fonoaudiologia.

Este estudo foi aprovado pelo protocolo No 59328/07 de 19 de outubro de 2007 
no Comitê de Ética em Pesquisa da UNAMA.

A pesquisa foi do tipo quanti-qualitativa descritiva e foi realizada no município de Belém, com 41 (quarenta e um) profissionais fonoaudiólogos no exercício de suas funções ou que as tenham exercido em alguma época de sua vida. Foram excluídos aqueles que não concluíram a graduação em fonoaudiologia ou que nunca exerceram a profissão.

Os fonoaudiólogos foram convidados a participar do estudo e os que aceitaram assinaram o termo de consentimento livre e esclarecido. Foi, então, aplicado um questionário que pretendeu investigar as questões éticas que envolvem a rotina dos fonoaudiólogos, os conhecimentos sobre bioética que os fonoaudiólogos possuem e se estes influenciam seu exercício profissional. Para capacitação na aplicação, assim como para a validação dos questionários, primeiramente ele foi aplicado aos fonoaudiólogos da Clínica de Fonoaudiologia da Universidade do Amazonas (CLIFA/UNAMA).

O critério adotado para arranjo dos dados dos questionários foi a própria sequência das questões no instrumento. As respostas foram analisadas e compiladas em tabelas. A análise dos resultados foi realizada por meio das informações compiladas dos autores e das legislações consultados, assim como da compilação das ideias contidas nas respostas mais frequentes dos questionários.

\section{Resultados e Discussão}

Foi verificado, que a maior parte dos fonoaudiólogos entrevistados (75\%) encontra-se na faixa etária de 20 a 30 anos e tem até 9 anos de formada. Ainda, 83\% destes fonoaudiólogos são especialistas e apenas 17\% têm mestrado. Isto demonstra que os sujeitos desta pesquisa possuem em sua maioria, a mesma formação acadêmica e a mesma vivência. As diferenças estão no nível sócio-econômico-cultural e formação moral, que são fatores bastante significativos, pois como cita Marins, as pessoas pensam de modo diferente, constroem seus conceitos em função de sua história de vida, do meio em que cresceram, do que lhes foi apresentado como modelo de certo e errado (6).

A maior parte dos entrevistados (75\%) refere que realizou/esclareceu um diagnóstico difícil e, apenas, 25\% não. Desses que realizaram, 15\% referem que houve necessidade de realizar um trabalho em equipe multidisciplinar para que houvesse o fechamento do diagnóstico; $10 \%$ relataram a dificuldade de lidar com a carga emocional envolvida, com a afetividade dos pacientes e seus familiares; $7 \%$ informaram que se tratou de caso envolvendo paciente cujo diagnóstico nunca foi fechado, $7 \%$ indicaram casos de 
perícia/exames ocupacionais; outros 7\% relataram casos de pacientes com distúrbios associados; $5 \%$ casos onde houve incompatibilidade de diagnóstico, 5\% de casos que envolveram possíveis alterações neonatais; $2 \%$ de casos de crianças que apresentavam alterações comportamentais; $2 \%$ informaram que solicitaram de procedimentos para confirmação dos dados; $2 \%$ apontaram dificuldade em diagnosticar uma disfagia esporádica; outros $2 \%$ dúvidas sobre hiperatividade e autismo; $2 \%$ confirmaram o diagnóstico de autismo; $2 \%$ citam que inovações na área hospitalar necessitam esclarecimento do parecer; $2 \%$ informam que foi difícil, porém enriquecedora como experiência profissional; $2 \%$ não comentaram.

Estes dados são corroborados pela visão de Goldim (5), pertinente à bioética em relação à necessidade de tomar decisões cautelosas. Assim como de Primo e demais autores (7), que defendem a bioética como integradora das questões humanísticas às técnicas para amenizar os dilemas da abordagem de um diagnóstico difícil.

Metade dos fonoaudiólogos entrevistados (52\%) informou que já realizou tratamento de pacientes terminais, em estado crítico ou com péssimo prognóstico. Destes fonoaudiólogos, $17 \%$ referiram o envolvimento de portadores de disfagia, 10\% que relataram que o paciente veio a óbito, $5 \%$ que os pacientes eram laringectomizados com metástase, $5 \%$ apontaram que os pacientes eram baixados na Unidade de Tratamento Intensivo (UTI), 2,5\% afirmaram que se tratava de paciente oncológico, 2,5\% relataram que era criança com diagnóstico de surdez, mas a mesma era ouvinte normal, 2,5\% relataram caso de péssimo prognóstico, 2,5\% apontaram caso de paciente autista e portador de deficiência auditiva, 2,5\% afirmaram se tratar de caso de Parkinson, ainda com manifestação esporádica e, por fim, 2,5\% indicaram ter havido a necessidade de um acompanhamento diferenciado para a família. Esses dados são confirmados por Lopes e Lautert (8), que consideram que o fato dos profissionais da saúde onde se inclui os fonoaudiólogos -, lidarem com a morte e a vida no mesmo contexto os deixa angustiados, temerosos e frustrados.

Quase a totalidade $(80,5 \%)$ dos fonoaudiólogos entrevistados já se deparou com um procedimento inadequado de um colega ou de outro profissional da saúde. Sobre esses procedimentos os dados colhidos apontam que: $21,5 \%$ dos fonoaudiólogos entrevistados conversaram com o colega ou com o outro profissional; $17 \%$ informaram ao paciente que utilizavam uma conduta diferente; $12,5 \%$ pediram reavaliação; $7 \%$ fizeram a discussão do caso; $5 \%$ dedicaram-se ao caso e ignoraram as condutas tomadas anteriormente; $5 \%$ deixaram a família escolher a melhor conduta, 2,5\% procuraram não magoar o colega, 2,5\% conduziramse do modo mais humilde o possível, 2,5\% acreditam na necessidade de muito diálogo, $2,5 \%$ sugeriram que a mãe conversasse com o profissional que fez o procedimento, $2,5 \%$ se 
decepcionaram com o profissional que fez o procedimento e que há tempos acompanhava o paciente.

Esses dados são explicados por Mendes (9), quando cita que nas instituições de saúde é comum os profissionais encontrarem colegas realizando procedimentos inadequados. Algumas atitudes tomadas pelos fonoaudiólogos entrevistados são explicadas por Ghiorzi (10) ao apontar que, muitas vezes, as relações interpessoais no trabalho são destrutivas, pois as pessoas têm dificuldade para estabelecer e manter relacionamentos construtivos, solidários, éticos, baseados na construção coletiva e no respeito pelas capacidades e limites do outro. Outras atitudes são explicadas por Backes, Lunardi e Lunardi Filho (11), que defendem a necessidade de compreender os limites dos demais profissionais como forma de promover a humanização nas instituições que trabalham com a saúde; ou então por Leddy e Pepper (12), ao afirmarem que respeitar o outro colabora na conquista da autonomia do profissional de saúde.

A maioria (71\%) dos fonoaudiólogos entrevistados alguma vez já teve um paciente que se aborreceu e/ou não colaborou durante um atendimento: 14,5\% referiram que os pacientes estavam cansados, irritados, nervosos e/ou agitados; 7\% comentaram que comunmente crianças se negarem a colaborar; $7 \%$ procuraram persuadir o paciente a colaborar; $5 \%$ citaram que foram casos de simulador; $5 \%$ que foram casos de terapia miofuncional; $5 \%$ que foram casos de exame ocupacional; $5 \%$ que foram casos de pacientes neurológicos; $5 \%$ informaram que o paciente não queria realizar o comando correto; $5 \%$ referiram que o paciente não gostou da atividade proposta; $2,5 \%$ citaram que se tratava de instalação de fonema; $2,5 \%$ que era caso de adulto com fobia em ambientes fechados; $2,5 \%$ que costumam sempre trabalhar com a família; 2,5\% que o paciente achava que sabia melhor qual tipo de aparelho auditivo colocar; $2,5 \%$ que o paciente não gostava do atendimento do fonoaudiólogo e $2 \%$ não comentaram.

Paiva e Pinotti (13) confirmam a ansiedade e as incertezas que acompanham o tratamento e que podem justificar o fato de alguns pacientes terem apresentado comportamentos aversivos durante o atendimento fonoaudiológico. Outra explicação poderia ser dada por Nogueira (14), quando cita que alguns pacientes percebem que estão ocorrendo situações inadequadas ao seu tratamento. Mas é o próprio autor (14) afirma que o profissional deve ser objetivo e esforçar-se para estimular o paciente a reverter a situação.

Mais da metade (64\%) dos fonoaudiólogos entrevistados não teve pacientes que pediram alteração no resultado de um determinado procedimento. Os 36\% que passaram por esta situação, fazem os seguintes comentários: $80 \%$ atribuem as solicitações aos casos de exames audiológicos; $13 \%$ generalizaram, referindo-se a pedidos de alterações de resultados de exames e 7\% informaram que conversaram com o paciente, explicando que não seria possível atender seu pedido e explicando os motivos. 
Segundo Leddy e Pepper (12), se o profissional tem autonomia, ele está disposto a assumir riscos. Portanto, se ele atender esse tipo de solicitação, terá responsabilidade sobre essas atitudes. Mendes (9) lembra que a bioética zela por preceitos morais, legais, sociais, culturais, assistenciais, econômicos, entre outros. Por isso, no Código de Ética da Fonoaudiologia (3) consta que o fonoaudiólogo deve utilizar os conhecimentos e recursos necessários, em favor do ser humano e da comunidade, assumir responsabilidades pelos atos praticados, respeitar o paciente e não permitir que este seja desrespeitado.

A metade (52\%) dos entrevistados nunca teve divergências com pacientes ou profissionais, já a outra metade (48\%) referiu que passou por problemas de relacionamento no âmbito profissional. Esses dados são ratificados por Nogueira (14) e Ghiorzi (10), quando descreveram a existência de conflitos no ambiente de trabalho, pois apontam que - para além da dificuldade para manter relacionamentos construtivos, solidários, éticos e baseados na construção coletiva e no respeito pelas capacidades e limites do outro -, existe também a necessidade de esclarecimento dos fatos, de discordar de certos posicionamentos e de determinados procedimentos. Por isso, Nogueira (14) acredita que é preciso manter o diálogo com os familiares e demais profissionais da equipe multidisciplinar. Já Oliveira (15) afirma que um bom relacionamento entre os membros da equipe é favorecido pelo conhecimento mútuo da área de trabalho de cada um. Oliniski e Lacerda (16) defendem a existência de um espaço relacional que propicie trocas e compartilhamentos. O Código de Ética da Fonoandiologia (3) preceitua que o fonoaudiólogo deve respeitar o paciente e impedir que ele seja desrespeitado. O papel ético do fonoaudiólogo é orientar-se pela humanização da assistência. Backes, Lunardi e Lunardi Filho (11) alertam que, para promover essa humanização, existe a necessidade de empreender estratégias que estimulem a participação e a comunicação efetiva entre todos nas relações da administração, envolvendo profissionais, pacientes e familiares.

A maioria $(71 \%)$ dos profissionais entrevistados não teve impasse na realização de pesquisa e apenas $29 \%$ relataram experiência com essa situação. Esses problemas podem ser explicados por Vasquez (17), que menciona que o cientista tem responsabilidade moral sobre a utilidade e sobre as consequências de suas pesquisas. Também por Engelhardt (18), que cita que as pesquisas envolvem riscos e possíveis consequências que necessitam de avaliação ética, cujos fundamentos filosóficos fornecem bases de conhecimento imprescindível, quando se trata de pesquisa com seres humanos.

Com relação aos conhecimentos sobre bioética, cerca de metade $(45 \%)$ dos fonoaudiólogos entrevistados destacaram que bioética é a ética aplicada às questões da saúde; $25 \%$ que ela contém normas de ética profissional; $12,5 \%$ que a disciplina estuda a relação entre os profissionais e os pacientes; $5 \%$ que ela é um indicador de como se 
trabalha com eficácia; $2,5 \%$ que ela consiste na prática constante entre os profissionais da saúde; $2,5 \%$ que envolve o conhecimento e os valores que cada indivíduo possui; $2,5 \%$ consideram-se atualizadas no assunto; $2,5 \%$ que conhecem pouco sobre bioética e 2,5\% não comentaram.

Pessini e Barchifontaine (19) justificam a facilidade de conceituação por metade da população entrevista, pois a palavra bioética combina conhecimentos biológicos e valores humanos, preocupando-se em estudar os dilemas éticos associados à área da saúde. Primo et al. (7) também, quando informam que a bioética procura integrar os aspectos técnico-científicos com os aspectos comportamentais e humanísticos, buscando amenizar os dilemas gerados por uma variável bio-psico-social, tratando de ações, de hábitos (virtudes) e de atitudes (caráter).

Dentre os entrevistados, $27 \%$ dos fonoaudiólogos entrevistados acreditam que a bioética auxilia no trato das questões abordadas neste estudo, pois é um padrão a seguir, são regras para disciplinar a conduta; $21,5 \%$ acreditam que ela auxilia por meio das orientações de conduta; $19,5 \%$ indicaram que a bioética é um auxílio, uma vez que melhora a relação entre os profissionais da saúde e os seus pacientes; $10 \%$ apontam que a bioética proporciona reflexão de conduta; $2,5 \%$ destacaram que ela proporciona maior interdisciplinaridade; $2,5 \%$ indicaram que a bioética dá conta dos conflitos morais que ocorrem no dia-a-dia; 2,5\% declaram que a bioética reafirma valores indispensáveis a sobrevivência social e profissional; $14,5 \%$ não comentaram.

Os comentários feitos pelos fonoaudiólogos entrevistados demonstram uma perspectiva positiva sobre a aplicação da bioética em seu cotidiano que encontra amparo em diversos autores como: Diniz e Guilhem (20), que acreditam que a bioética deve buscar estratégias conciliatórias para os conflitos morais e, como nunca atingirá a verdade absoluta válida para todos, precisa respeitar o pluralismo e a diferença moral das sociedades; Pessini e Barchifontaine (19), que afirmam que a bioética se preocupa em estudar os dilemas éticos associados à área da saúde, priorizando a proteção do ser humano; França (21), que considera que a bioética gera influências positivas e negativas na sociedade atual; L'Abbate (22), que defende que os profissionais de saúde precisam de aprimoramento educacional para desenvolver a reflexão sobre as dificuldades na convivência organizacional do cotidiano; Costa Jr. (23), que refere que a bioética resguarda o ser, pois coloca limites éticos para promover a humanidade nas ações que tocam a vida; Jardilino e Herrero (4), que relatam que é uma preocupação atual da fonoaudiologia, o caráter humanístico do fonoaudiólogo e sua inserção no contexto social; e Goldin (5), que informa que a interação da bioética com a fonoaudiologia é extremamente fértil. 


\section{Conclusão}

Várias situações na rotina profissional diária do fonoaudiólogo foram apontadas: a maioria dos profissionais já realizou e/ou esclareceu um diagnóstico difícil, já se deparou com um procedimento inadequado de um colega ou de outro profissional da saúde e já teve um paciente que, pelo menos alguma vez, se aborreceu e/ou não colaborou durante um atendimento. Cerca de metade dos fonoaudiólogos já realizou tratamento de pacientes terminais, em estado crítico ou com péssimo prognóstico e já passou por problemas de relacionamento no âmbito profissional. Um terço dos profissionais já tiveram pacientes que pediram alteração no resultado de um determinado procedimento e já tiveram impasse na realização de pesquisa.

Os sujeitos desta pesquisa possuem, em sua maioria, a mesma formação acadêmica e a mesma vivência profissional. As diferenças entre eles estão no nível sócio-econômico-cultural e na formação moral. Estas, portanto, podem ser responsáveis pela variação das respostas. Além disso, a grande maioria demonstrou ter algum conhecimento teórico sobre bioética.

Foram identificados indícios que comprovaram a influência da bioética no exercício profissional da fonoaudiologia: envolve regras para disciplinar a conduta profissional, portanto orienta essa conduta, proporciona reflexão de conduta e interdisciplinaridade, facilitando lidar com os conflitos que ocorrem no cotidiano, melhora a relação entre os profissionais da saúde e os seus pacientes e reafirma valores indispensáveis à sobrevivência social e profissional.

Os dados mostram que várias questões éticas envolvem a rotina dos fonoaudiólogos, como citado acima. Também mostram que estes profissionais possuem certos conhecimentos sobre a bioética e reconhecem o auxílio que esta ciência pode significar em seu desempenho. Por isso, muitas pesquisas precisam ser feitas para detalhar a aplicação da bioética na atuação específica do fonoaudiólogo.

\section{Referências}

1. Ferraz OLM. Questionamentos judiciais e a proteção contra o paciente: um sofisma a ser corrigido pelo gerenciamento de riscos. Bioética. 1997; 5(1):7-12 [citado em 11 mai. 2007]. Disponível em: http://www.crmma.org.br/revista/bio1v5/questiona.html.

2. Pessini L, Barchifontaine CP. Problemas atuais de Bioética. São Paulo: Loyola; 2007.

3. Conselho Federal de Fonoaudiologia. Código de Ética da Fonoaudiologia. Resolução CFFa no 305/2004,de 06 março de 2004. Dispõe sobre a aprovação do Código de Ética da Fonoaudiologia, e dá outras providências. Diário Oficial da República Federativa do Brasil, DF, 9 mar., 2004. 
4. Jardilino JRL, Herrero E. Fonética da Ética Profissional à Antropoética: contribuição para formação profissional. Revista da Sociedade Brasileira de Fonoaudiologia 2000; 5(7): 11-17.

5. Goldim JR. Bioética e Fonoaudiologia [Internet]. Porto Alegre: José Roberto Goldim. 1997 Fev. - [citado em 02 jun. 2007]. Disponível em: www.ufrgs.br/bioética/fonoaud.htm

6. Marins L. Por que os outros não são iguais a mim? [Internet]. São Paulo: Guia RH. 1998 [citado em 02 dez. 2007]. Disponível em: http://www.guiarh.com.br/pp15.htm.

7. Primo WQSPP, Primo GRP, Cunha FMP, Garrafa V. Estudo bioético da informação do diagnóstico do HPV em uma amostra de mulheres no Distrito Federal. Bioética. 2004; 12(2):33-51 [citado em 19 dez. 2007]. Disponível em: http://www.portalmedico.org.br/ revista/bio12v2/artigos/Artigo3.pdf.

8. Lopes MJ, Lautert L. A saúde das trabalhadoras da saúde: algumas questões. In: Haag GS, Lopes MJM, Schuck JS, organizadoras. A enfermagem e a saúde dos trabalhadores. 2 ed. Goiânia: AB; 2001. p.109-40.

9. Mendes EG. Diagnósticos e atividade profissional. Porto Alegre: Artes Médicas; 2006.

10. Ghiorzi AR. O quotidiano dos trabalhadores em saúde. Texto Contexto Enferm. 2003; 12(4):551-58.

11. Backes DS, Lunardi VL, Lunardi Filho WD. Hospital humanization as an expression of ethics. Revista Latino-Americana de Enfermagem. 2006; 14(1):132-135.

12. Leddy S, Pepper JM. Conceptual bases of professional nursing. Philadelphia: J. B. Lippicontt Company; 1993.

13. Simongini EC. O adoecer de câncer e o processo de individuação. [monografia] Marilia (SP): Universidade de Marilia; 2005. Disponível em: http://www.symbolon.com.br/monografias/.

14. Nogueira JC. Ética e responsabilidade pessoal. In: Morais R, Nogueira JC. Filosofia, Educação e Sociedade: ensaios filosóficos. Campinas: Papirus; 1989.

15. Oliveira BSA. O silêncio da singularidade. In: Oliveira ST. Fonoaudiologia Hospitalar. São Paulo: Lovise; 2003. p.63-70.

16. Olinski SR, Lacerda MR. As Diferentes Faces do Ambiente de Trabalho em Saúde. Cogitare Enferm 2004; 9(2):43-52.

17. Vázquez AS. Ética. Rio de Janeiro: Civilização Brasileira; 1993.

18. Engelhardt Jr. HT. Fundamentos da Bioética. São Paulo: Loyola; 1998.

19. Vieira TC. Bioética e Direito. São Paulo: Jurídica; 2003.

20. Diniz D, Guilhem D. O que é Bioética? São Paulo: Brasiliense; 2002.

21. França GV. Fundamentos de Medicina Legal. Rio de Janeiro: Guanabara; 2005.

22. L’Abbate S. Educação em saúde: uma nova abordagem. Cadernos de Saúde Pública. 1994; 10(4):481-490.

23. Costa Jr. AS. Bioética. Cadernos de Saúde. 1997; 2(1):155-176.

\section{Recebido: 02/02/2011 Aprovado: 30/05/2011}

